\title{
Prevalence and awareness of type 2 diabetes mellitus among adult population in Mwanza city, Tanzania
}

\author{
CAROLYNE C. RUHEMBE* , THEOBALD C.E. MOSHA and CORNELIO N.M. NYARUHUCHA \\ Sokoine University of Agriculture, Department of Food Science and Technology, P. O. Box 3006, Morogoro, \\ Tanzania
}

\begin{abstract}
Type 2 diabetes mellitus (T2DM) prevalence is increasing rapidly around the world. This crosssectional study was conducted to assess the prevalence and awareness of type 2 diabetes mellitus in Mwanza city, Tanzania. A multistage random sampling technique was used to obtain representative subjects. Information about causes and risk factors were collected using structured questionnaire. In addition, community random blood glucose testing was employed to identify those at risk. Subjects with $\geq 200 \mathrm{mg} / \mathrm{dl}$ on the following day were subjected to fasting blood glucose testing and they were confirmed to have T2DM if they had blood glucose level of $\geq 126 \mathrm{mg} / \mathrm{dl}$. In each subject, height, weight, waist and hip circumferences and total fat and fat free mass were measured using standard procedures. A total of 640 participants were included in this study, $55 \%$ were females and $45 \%$ were males. Mean age of the respondent was $43.84 \pm 10.80$ years. Most (46.4\%) respondents were in the age group 30-40 years. Mean age for females was $44.0 \pm 10.31$ years while for males was $43.6 \pm 11.3$ years (Table 1$)$. Overall prevalence of T2DM was $11.9 \%,(n=76)$. Prevalence was high in females $(7.2 \% ; n=46)$ than in males $(4.7 \% ; n=30)$. The age between $41-50$ years had the highest prevalence of T2DM $28.6 \%$ followed by $51-60$ years age group (17.2\%). Significant independent associations were found for age (OR 3.88, 95\% Cl: 2.16-6.95) positive first degree relative with T2DM (OR 1.34; 95\%C: 1.101.64) alcohol intake (OR 1.23; 95\% Cl: 1.02-1.48) smoking (OR 3.86; $95 \% \mathrm{Cl}: 2.57-5.78$ ) and hypertension (OR $0.096 ; 95 \% \mathrm{Cl}: 1.954-18.251)$. Only $49.2(\mathrm{n}=315)$ of the respondents knew about the causes and symptoms of T2DM. Public education on T2DM should be emphasized and routine measurement of blood glucose levels is recommended among adults.
\end{abstract}

Keywords: diabetes, type 2, prevalence, awareness, urban, Tanzania

\section{Introduction}

Diabetes is a chronic, non-communicable disease, characterised by high levels of glucose in the blood. It occurs either because the pancreas stops producing the hormone insulin (Type 1 diabetes), or through a combination of the pancreas having reduced ability to produce insulin alongside the body being resistant to its action (Type 2 diabetes) (OECD (2011). Prevalence of type 2 diabetes mellitus (T2DM) is now increasing rapidly around the world and emerging as a global health problem that is expected to reach pandemic levels by 2030 (Wild et al., 2004; Shaw et al., 2010). It is estimated that 439 million people globally, will have T2DM by 2030 (Chamnan et al., 2011). This increase will be noticeable in developing countries where the number of people with T2DM is expected to increase from 84 million to 228 million people (IDF, 2009), and this would be more than $75 \%$ of the world population (Egede \& Elis, 2010).

Chronic diseases, including T2DM, have been rising in sub Saharan Africa currently due to urbanization and changing lifestyle characteristics. With the increase of life expectancy which causes elderly population to continue growing and eventually, the burden of chronic diseases has been increasing in recent years (Gillepsie \& Haddad, 2003).

\footnotetext{
${ }^{*}$ Correspondence: Carolyne Ruhembe; E-mail: cruhembe@gmail.com
} 
In Tanzania, between 18 and $24 \%$ of deaths are attributable to non-communicable diseases (NCD) and injuries (AMMP, 1997). The non-communicable diseases contributing most to overall mortality are cardiovascular diseases, cancer, central nervous system diseases, diabetes and chronic respiratory disease (AMMP, 1997). In Tanzania, there is a marked variation in the prevalence of diabetes among rural (<2\%) and urban ( $>5 \%$ ) populations (Aspray et al., 2000) and higher in people of Asian origin (>7\%) (Ramaiya et al., 1991).

Diabetes is a silent disease in which many sufferers become aware that they are sick only when they develop one or more of its life-threatening complications (Wee et al., 2002). Complications from T2DM include blindness, renal disease and amputation among others (Dart et al., 2013). In Tanzania limited efforts have been devoted to educate the public about diabetes through the public media, but the impact of such efforts has yet to be evaluated (TDA, 2005). General knowledge on diabetes mellitus to the community can assist in early detection of the disease and reduce the incidence of complications. Overweight, obesity, unhealthy diet, tobacco use, alcohol consumption, high blood pressure, high cholesterol levels, and lack of physical activity have been described as the major risk factors for non-communicable diseases including diabetes (WHO, 2009).

It is not known how much the public actually knows about diabetes through the current programmes. Knowledge on the level of public is crucial to health educators to plan for future programmes related to T2DM (Cullen \& Buzek, 2009). Furthermore there are limited reports available on the level of knowledge on diabetes in the general population in Tanzania (Nguma, 2010). It is important for the public to be aware of T2DM because knowledge is a critical component of behavioural change (Mahrooqui et al., 2013). Once awareness is created, people are more likely to participate in prevention and control measures (Ericksson et al., 2001). The objective of this study was therefore, to determine the prevalence and awareness of T2DM among residents of Mwanza city, Tanzania. The information from this study will be useful in educating the communities on risks factors and possible interventions and control measures against T2DM.

\section{Material and Methods}

\section{Study area}

The study was conducted in Mwanza city, Tanzania which is located in the north-western part of Tanzania between latitude $1^{\circ} 30^{\prime}-3^{\circ} \mathrm{O}^{\prime} \mathrm{S}$ and longitudes $31^{\circ} 45^{\prime}-34^{\circ} 10^{\prime} \mathrm{E}$. The estimated population is 706,453 with $3.2 \%$ growth rate. Majority of Mwanza people a self employed involved in petty business, peasantry and micro fishing activities. The average per capita income of Mwanza city is US\$ 21 per month (URT, 2012).

\section{Sampling and sample size}

A multistage random sampling technique was used to obtain representative districts and wards as described by Kothari (2006). Six wards from Ilemela and Nyamagana districts were randomly selected. From each ward, four streets were randomly selected and from each street 27 households were randomly selected by using random table numbers. At the household, subjects were stratified by sex. From the age group of 30 years and above a representative sample was randomly selected. Sample size was calculated using the formula by Daniel (1999) for prevalence studies. Using a prevalence rate of T2DM in Tanzania as 2.6\% (Sobngwi et al., 2001), the sample size was estimated at 640 subjects ( 320 per district) was obtained. The study population comprised of adults (males and females) aged $\geq 30$ years residing in Mwanza city for at least 3 months prior to the study. Mentally ill people and pregnant women were excluded from the study. A cross-sectional study design was 
employed to determine the prevalence and identify those at risk of T2DM. A fasting blood glucose testing was done twice for those with elevated blood sugar to confirm the cases.

\section{Data collection}

A structured questionnaire was constructed to solicit information from the subjects. Seven aspects of awareness concerning Type 2 Diabetes mellitus were examined from the study namely. These were knowledge of diabetes, symptoms, causes, group most affected, management of the disease, risks factors and complications of diabetes. Section three solicited information about lifestyle characteristics and other associated risks for type 2 diabetes mellitus. The questionnaire was pretested for its validity and was amended accordingly prior to administration. Questionnaires were administered using face to face interview in the morning, at noon and afternoon and also measurements were taken during the same time. For those subjects with increased blood glucose level of $\geq 200 \mathrm{mg} / \mathrm{dl}$ fasting blood glucose was done on them on the following day.

\section{Anthropometric measurements}

Weight, height, and waist circumference (WC) were measured according to standard procedures (WHO, 2004). Weight was measured using a standard weighing scale (digital electronic SECA scale; Model 8811021659, Germany) that was kept on a firm horizontal surface. The subject's weight was recorded to the nearest $0.1 \mathrm{~g}$. Height was measured by using a stadiometer whereby subjects were requested to stand upright without shoes with their back against the wall and heels put together, in a V-shape and looking forward. Body mass index was calculated using the formula, weight $(\mathrm{kg}) /$ height $\left(\mathrm{m}^{2}\right)$ and categorized as proposed described by WHO (2004). Waist circumference was measured by a non-stretchable measuring tape to the nearest $0.1 \mathrm{~cm}$ taken at the mid -point between the costal margin and iliac crest, with the subject standing erect in a relaxed position and feet placed $25-30 \mathrm{~cm}$ apart. The waist circumference was recorded to the nearest $0.1 \mathrm{~cm}$. Hip circumference was measured at the level of the greater trochanters (widest portion of the hip) using a non-stretchable tape while the subject was standing with arms on side and feet together. The hip circumference was recorded to the nearest $0.1 \mathrm{~cm}$. Waist and hip circumferences were used to determine waist hip ratio. Information on demographic characteristics, lifestyle behaviour, risk behaviours and awareness were collected.

Blood pressure (BP) was measured by using standard protocol. Three serial measurements of BP were taken one minute apart, using a digital blood pressure monitor sphygmomanometer ( $\mathrm{CH}-432 \mathrm{~B}$, Citizen Systems Japan Co Ltd) with subjects in the sitting position. The BP was measured after the subject had rested for at least 5 minutes. Total body fat composition was determined by using Bi-electric impedance (BF 905, Maltron, UK) (BIA) method. A subject was requested to stand on the electrodes without shoes and minimum clothing.

\section{Biochemical measurement}

Random blood glucose (RBG) of the subjects was measured at the time of the interview by using a standardized Gluco Plus machine (Glucometer Type 25 KB JPG) using capillary finger prick method. Subjects with RBG $\geq 200 \mathrm{mg} / \mathrm{dl}$ were requested to do a follow up fasting plasma glucose (FPG) whereby they were requested to fast for at least $8 \mathrm{hrs}$ to confirm if they were normal or diabetic. A person was confirmed to be diabetic when Fasting Plasma glucose was $\geq 126 \mathrm{mg} / \mathrm{dl}$.

\section{Ethical consideration}

Ethical clearance certificate to conduct this study was obtained from the Medical Research Coordinating Committee of the National Institute for Medical Research (NIMR/HQ/R.8a/Vol. IX/1322) after the objectives and benefits of the study were explained to the subjects. A written informed 
consent was sought before any of the individual was enrolled in the study. Confidentiality of the collected data was assured. Permission to conduct the study was obtained from Mwanza Region and from Ilemela and Nyamagana district health authorities.

\section{Data analysis}

Comparison was done by student t-test for continuous variables and $\chi_{2}$-test for categorical variables. Multiple regression analyses were conducted to control the effects of potential confounding factors. All diabetic risk factors and other potential risk factors, were entered into regression model, with diabetes ( $0=$ no, $1=y e s$ ) as the dependent variables. Categorical data were expressed as frequency and percentages and compared by Chi-square test and non-parametric test in different subgroups or proportion in case of the violation of normal distribution. Normal waist hip ratio for women was $<0.80$, overweight $0.80-0.84$ and $\geq 0.85$ was obesity while in men $<0.90$ was normal weight, 0.90-0.99 was overweight and $\geq 1$ was obese (WHO, 2008b). Body-fat-percent categories for this analysis were as follows: $10 \%$, under-body-fat, $10 \%$ to $20 \%$ normal-fat, $20 \%$ to $25 \%$ over-fat and >25\% higher-body-fat (Yamashita et al., 2012).

\section{Results}

\section{Demographic, biochemical and anthropometric characteristics}

A total of 640 participants were included in this study of whom 352 (55\%) were females and 288 (45\%) were males. More respondents had 30-40 years (46.4\%) while age group $>60$ years were few (11\%). The mean age and standard deviation for the study participants (SD) was $43.84 \pm 10.80$ years. Mean age for females was $44.0 \pm 10.31$ years while for males was $43.6 \pm 11.3$ years (Table 1 ). There were $64.5 \%$ respondents having primary level of education while only $9.8 \%$ were having college level of education where males showed significantly $(\mathrm{p}<0.05)$ higher education level than females. There were $34.37 \%$ respondents dealing with petty businesses while $28.4 \%$ were waged employees. In the study population $68.7 \%$ were married $17.8 \%$ singles, $5.4 \%$ divorced, and $7.9 \%$ widowed. Most of the respondents $47.65 \%$ earned less or equal to US\$43.75 per month while only $1.1 \%$ earned higher or equal to US\$625 per month. Males earned significantly higher incomes than females counterparts $(p<0.05)$.

The mean percentage fat mass for the study population was $24.42 \pm 10.31$. The mean body fat mass percentage for females $(27.86 \pm 10.52 \%)$ was significantly higher than that of the males $(20.07 \pm$ $8.20 \%)(p<0.05)$. The mean systolic blood pressure was significantly higher in males $(139.11 \pm 68.04$ $\mathrm{mmHg}$ ) than in females $(128.82 \pm 20.11 \mathrm{mmHg})$. The overall mean BMI was $25 \pm 5.1 \mathrm{~kg} / \mathrm{m}^{2}$. The mean BMI for females was significantly higher $\left(26.26 \pm 5.50 \mathrm{~kg} / \mathrm{m}^{2}\right)$ than of males $\left(23.42 \pm 4.14 \mathrm{~kg} / \mathrm{m}^{2}\right)$ $(p<0.05)$. The overall mean blood glucose level was $103.82 \pm 47.52 \mathrm{~mm} / \mathrm{dl}$ and it was similar between male and female respondents (Table 1 ).

\section{Prevalence of Type 2 diabetes mellitus by age and sex}

During this study $76(11.9 \%)$ respondents were diagnosed with type 2 diabetes mellitus with mean value of $103.8 \pm 47.5$ Table 1 . The crude prevalence of diabetes was $4.7 \%$ for males and $7.2 \%$ for females figure 1. impaired fasting glucose (IFG) $(110-125 \mathrm{mg} / \mathrm{dl}$ ) was $3 \%$ to $3.9 \%$ for males and females respectively Figure 1. Diabetes and IFG was found to be higher in females than in males. Age has an overall effect on diabetes. It was found to be the most important factor. Diabetes tends to increase with increasing age as it is shown to be high in $41-60$ years and tend to decrease in $>60$ years for both men and women $(\mathrm{p}<0.05)$ Table 2. 
Table 1: Socio-demographic, biochemical and anthropometric characteristics

\begin{tabular}{|c|c|c|c|c|}
\hline Characteristic & Value/response & $\begin{array}{l}\text { Total No. (\%) } \\
(n=640)\end{array}$ & $\begin{array}{l}\text { No. females (\%) } \\
(n=352)\end{array}$ & $\begin{array}{l}\text { No. males (\%) } \\
(n=288)\end{array}$ \\
\hline \multirow[t]{4}{*}{ Education level } & Informal & $64(10.00)$ & $46(13.120$ & $18(6.22) *$ \\
\hline & Primary & $413(57.22)$ & $248(70.510$ & $165(57.39)$ \\
\hline & Secondary & $100(62.53)$ & $31(8.82)$ & $69(24.00)$ \\
\hline & College & $63(9.81)$ & $27(7.71)$ & $36(12.51)$ \\
\hline \multirow[t]{4}{*}{ Marital status } & Single & $114(17.82)$ & $46(13.11)$ & $68(23.63)$ * \\
\hline & Married & $440(68.70)$ & $236(67.00)$ & $204(70.83)$ \\
\hline & Divorced & $35(5.43)$ & $25(7.13)$ & $10(3.52)$ \\
\hline & Widow/widower & $51(7.92)$ & $45(12.84)$ & $6(2.12)$ \\
\hline \multirow[t]{4}{*}{ Age group (years) } & $30-40$ & $297(46.40)$ & $154(43.84)$ & $143(49.72)$ \\
\hline & $41-50$ & $174(27.13)$ & $100(28.46)$ & $74(25.71)$ \\
\hline & $51-60$ & $98(15.34)$ & $62(17.67)$ & $36(12.51)$ \\
\hline & $>60$ & $71(11.09)$ & $36(12.51)$ & $35(12.22)$ \\
\hline \multirow[t]{5}{*}{ Income per month } & $<43.74 \$$ & $305(47.60)$ & $190(54.00)$ & 115 (39.91* \\
\hline & $43.74-62.5 \$$ & $183(28.52)$ & $102(29.2)$ & $81(28.12)$ \\
\hline & $62.5 \$-311.875 \$$ & $131(20.44)$ & $54(15 \cdot 32)$ & $77(26.71)$ \\
\hline & $312.5 \$-624.375 \$$ & $14(2.13)$ & $2(0.65)$ & $12(4.22)$ \\
\hline & $>625 \$$ & $7(1.12)$ & $4(1.17)$ & $3(1.00)$ \\
\hline \multirow[t]{8}{*}{ Occupation } & Formal sector & $54(18.81)$ & $35(9.92)$ & $89(13.91)$ \\
\hline & Private sector & $20(6.90)$ & $17(4.83)$ & $37(5.82)$ \\
\hline & Self employed & $31(10.91)$ & $25(7.15)$ & $56(8.84)$ \\
\hline & Farmer & $80(27.84)$ & $61(17 \cdot 32)$ & $141(22.00$ \\
\hline & Housewife & $5(1.72)$ & $72(20.58)$ & $77(12.00)$ \\
\hline & Not working & $1(0.33)$ & $0(0.00)$ & $1(0.23)$ \\
\hline & Entrepreneurship & $83(28.85)$ & $137(38.93)$ & $220(34.44) *$ \\
\hline & Students & $14(4 \cdot 91)$ & $5(1.44)$ & $19(3.00)$ \\
\hline \multirow{7}{*}{$\begin{array}{l}\text { Biomedical/Anthrop } \\
\text { ometric }\end{array}$} & Age in (years) & $43.82 \pm 10.81$ & $44.03 \pm 10.31$ & $43.63 \pm 11.42$ \\
\hline & Fat mass (\%) & $24.42 \pm 10.31$ & $27.86 \pm 10.52$ & $20.07 \pm 8.20 *$ \\
\hline & Blood glucose levels $(\mathrm{mm} / \mathrm{dl})$ & $103.82 \pm 47.52$ & $105.72 \pm 54.91$ & $101.52 \pm 36.51$ \\
\hline & Systolic pressure ((mmHg) & $133.41 \pm 48.21$ & $128.82 \pm 20.11$ & $139.11 \pm 68.04^{*}$ \\
\hline & Diastolic pressure (mmHg) & $83.51 \pm 14.02$ & $82.22 \pm 13.41$ & $83.52 \pm 15.13$ \\
\hline & $\mathrm{BMI} \mathrm{kg} / \mathrm{m} 2$ & $25.03 \pm 5.11$ & $26.26 \pm 5.50$ & $23.42 \pm 4.14^{*}$ \\
\hline & Waist/hip ratio & $0.90 \pm 0.22$ & $0.89 \pm 0.23$ & $0.90 \pm 0.13^{*}$ \\
\hline
\end{tabular}

Mean with SD for clinical and frequency and percentages for socio-demographic data. Significant at * $\mathrm{p}=<0.05$ by student $t$ test and $\chi^{2}$ 


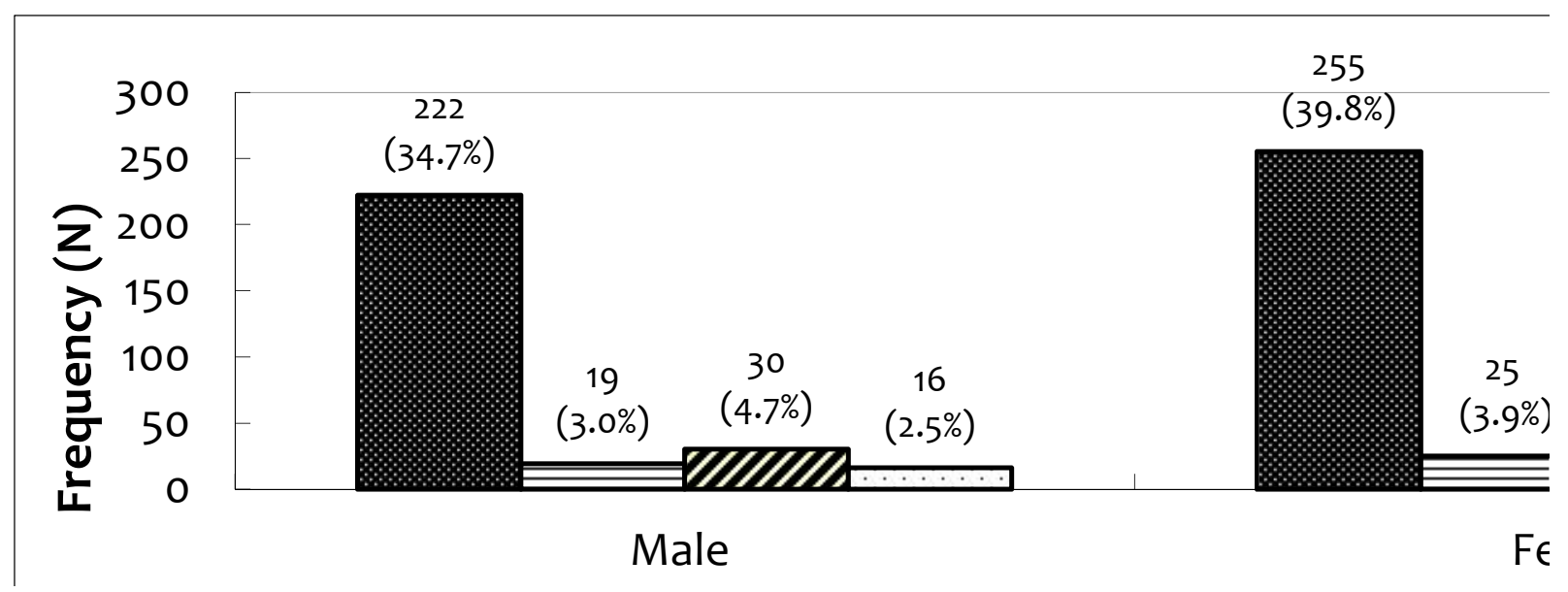

Figure 1: Prevalence of type 2 diabetes and impaired fasting glucose $(n=640)$

Diabetes prevalence increased with increasing age, and it was highest in the 41-60 years old group (Table 2).

Table 2: Prevalence of type 2 diabetes mellitus by sex and age (\%)

\begin{tabular}{llll}
\hline Age group & Male $(\mathbf{n}=\mathbf{2 8 8})$ & Female $(\mathbf{n}=\mathbf{3 5 2})$ & Total $(\mathbf{n}=\mathbf{6 4 0})$ \\
\hline $30-40$ & $3(10.0)$ & $7(15.2)$ & $10(13.2)$ \\
$41-50$ & $14(46.7)$ & $16(34.8)$ & $30(39.5)$ \\
$51-60$ & $9(30.0)$ & $19(41.3)$ & $28(36.8)$ \\
$>60$ & $4(13.3)$ & $4(8.7)$ & $8(10.5)$ \\
Total & $30(4.7)$ & $46(7.2)$ & $76(11.9)$ \\
\hline
\end{tabular}

Significant at $p<0.05$

\section{Relationship between diabetes and some selected risk factors}

Univariate logistic regression analysis of percentage fat mass, BMI, hypertension systolic blood pressure, diastolic blood pressure, waist hip ratio, smoking behaviour, alcohol intake, age, sex, hypertension and first class relative with T2DM was conducted. The model revealed that other variables were not significantly related to T2DM, therefore were removed from the model. Significant variables remained in the model for further analysis by binary logistic regression adjusting for confounding factors by backward conditional. Significant independent association were found for Age (OR 7.36, 95\% Cl 3.08-17.56) positive first degree relative (OR 1.16; 95\%, 95\%C1: 0.56-2.42) sex (OR 0.22; 95\% Cl: 0.09-52) smoking, (OR 66.9; Cl: 28.97-154.49) and hypertension (OR 0.096; 95\% Cl: 1.954-18.251). BMI, systolic blood pressure, and diastolic blood pressure were not significantly related with $\mathrm{T} 2 \mathrm{DM}$. 
Table 3: Multivariate regression models for the relationship between T2DM and some selected risk factors

\begin{tabular}{|c|c|c|c|c|c|}
\hline Variable & Response/Value & Frequency & OR & P-value & $95 \% \mathrm{Cl}$ \\
\hline \multirow[t]{2}{*}{ Sex } & Male & 288 & & & \\
\hline & Female & 352 & 0.22 & $0.001 *$ & $0.09-0.52$ \\
\hline \multirow[t]{2}{*}{ Age } & $\geq 40$ & 342 & & & \\
\hline & $\leq 40$ & 298 & 7.36 & $0.000 *$ & $3.08-17.56$ \\
\hline \multirow[t]{2}{*}{ Smoking } & Smokers & 106 & & & \\
\hline & Non smokers & 534 & 66.90 & $0.000 *$ & $28.97-154.49$ \\
\hline \multirow[t]{2}{*}{$1^{\text {st }}$ Degree relative to T2DM } & Yes & 156 & & & \\
\hline & No & 484 & 1.168 & $0.031^{*}$ & $0.56-2.42$ \\
\hline \multirow[t]{2}{*}{ SBP } & $\geq 140$ & 477 & & & \\
\hline & $\leq 140$ & 163 & 0.57 & 0.212 & $0.24-1.36$ \\
\hline \multirow[t]{2}{*}{ DBP } & $\geq 90$ & 169 & & & \\
\hline & $<90$ & 471 & 0.618 & 0.298 & $0.25-1.52$ \\
\hline \multirow[t]{2}{*}{ BMI } & High & 286 & & & \\
\hline & Low & 354 & 0.69 & 0.342 & $0.33-1.46$ \\
\hline \multirow[t]{2}{*}{ Hypertension } & Yes & 232 & & & \\
\hline & No & 408 & 0.096 & $0.002 *$ & $1.954-18.25$ \\
\hline
\end{tabular}

*Significant at $p<0.05$

Relationship between T2DM and some selected awareness variables

Only $49.2 \%$ of the respondents reported that they knew about a condition called diabetes. Only $32.2 \%$ of the respondents were aware of the symptoms of diabetes. Knowledge of the causes of diabetes was very low with $83 \%$ of the respondents didn't know the causes of T2DM. Slightly over half $(54.2 \%)$ of the respondents were not aware which age is affected by the disease. Moreover $45.5 \%$ of the respondents did not know how to manage the disease through diet, exercises and medication. Regarding knowledge of the risk factors for diabetes it was revealed that, only $29.1 \%$ of the respondents had knowledge of the risk factors for T2DM $\left(\chi_{2}^{2}=57.16 p<0.05\right)$. Moreover, only 26.3 $\%$ of the respondents were aware of the complications associated with diabetes $\left(\chi^{2}=60.57 p<0.05\right)$.

Table 4: Relationship between T2DM mellitus and selected awareness variables

\begin{tabular}{|c|c|c|c|c|c|c|}
\hline Awareness/Knowledge & Response & Number & $\%$ & df & P-Value & $x^{2}$ \\
\hline \multirow[t]{2}{*}{ Diabetes disease } & Yes & 315 & 49.2 & 3 & 0.870 & 0.07 \\
\hline & No & 325 & 50.8 & & & \\
\hline \multirow[t]{2}{*}{ Symptoms } & Know & 206 & 32.2 & 9 & $0.036 *$ & 17.97 \\
\hline & Don't know & 434 & 67.8 & & & \\
\hline \multirow[t]{3}{*}{ Causes } & $\begin{array}{l}\text { Too much eating and } \\
\text { sedentary lifestyle }\end{array}$ & 73 & 11.4 & 12 & 0.136 & $17 \cdot 37$ \\
\hline & Inherited & 31 & 4.8 & & & \\
\hline & Not aware & 536 & 83.8 & & & \\
\hline \multirow[t]{3}{*}{ Age affected } & Adults aged $>40$ & 215 & 33.6 & 12 & 0.188 & 16.07 \\
\hline & All age groups & 78 & 12.2 & & & \\
\hline & Don't know & 347 & 54.2 & & & \\
\hline \multirow[t]{2}{*}{ Management } & Diet and exercise & 349 & $54 \cdot 5$ & 18 & $0.000 *$ & 111.77 \\
\hline & Don't know & 291 & $45 \cdot 5$ & & & \\
\hline \multirow[t]{2}{*}{ Risk factors } & Know & 186 & 29.1 & 3 & $0.000 *$ & 57.16 \\
\hline & Don't know & 454 & 70.9 & & & \\
\hline \multirow[t]{2}{*}{ Complications } & Aware of & 168 & 26.3 & 3 & $0.000 *$ & 60.57 \\
\hline & Not aware & 472 & 73.8 & & & \\
\hline
\end{tabular}

*Significant at $p<0.05$ 


\section{Discussion}

The crude prevalence estimates rates of type 2 diabetes and IFG in the study were $11.9 \%$ and $6.9 \%$ respectively. Previous studies in urban Tanzania have reported lower prevalence of diabetes (Ramaiya et al., 1991; Aspray et al., 2000). In a recent national survey, 9\% of 5,860 adults (25-64years) were found to have raised fasting blood glucose (WHO, 2012). It should be noted that the study by Aspray et al. (2000) used the world population, rather than national or district level population, and the findings were adjusted for the age standardization. In the current study the crude prevalence for T2DM and IFG were not adjusted for age. In our study, women had a significant higher prevalence of diabetes than men. Similar findings were reported in the recent national survey (WHO, 2012). In Nigeria, Ekpenyong et al. (2012) also found diabetes to be higher among females than males. However, in previous surveys in Tanzania, the prevalence of diabetes in males was similar to that in females (Ramaiya et al., 1991; Aspray et al., 2000).

Generally, worsening glycaemic status was associated with increasing age, sex, smoking behaviour and first class relative with T2DM. Globally, age and sex have been identified as risk factors for diabetes mellitus. Generally, worldwide diabetes prevalence is similar in men and women, but it is shown to be slightly higher in men greater than 60 years of age (Wild et al., 2004). In this study, diabetes was more prevalent in the women of 51-60 years group. The combined effect of a greater age has an overall effect on diabetes. Age was found to be the most important factor because diabetes tends to increase with increasing age (Cowie et al., 2006). Advanced age showed triple risks of developing T2DM as compared to younger ages. Globally, the largest proportion of people with T2DM is between 40-59 years (Whiting et al., 2011) which was also reflected in this study. The high diabetes prevalence in Mwanza and elsewhere in Tanzania is likely to be associated with several reasons. For instance, life expectancy has slightly increased (MoHSW/IHI/NIMR/WHO, 2013) leading to increased risks to age related metabolic disorders and secondly there is an increased risk of overweight, obesity and sedentary type of activities which have continued to overshadow genetic causes (Nardo et al., 2009; Frank, 2010; Travers \& McCarthy, 2011; WHO, 2012).

In this study the mean percent fat mass and mean BMI were found to be significantly higher in females than males. However, the mean systolic blood pressure was significantly higher in males than females. On the other hand, fat mass, BMI level, waist-hip ratio was higher among females than males indicating increasing risk for developing chronic diseases. A study by Wang et al. (2005) suggested that, waist circumference and waist-hip ratio (measures of central obesity) were more positively and more significantly associated with T2DM than BMI in males.

Subjects having first class relative with T2DM were more likely to develop T2DM than subjects without positive first class relatives. The present study showed a significant association between family history and incident T2DM, with no remarkable sex difference in the association. These findings are in agreement with previous study elsewhere (Wada et al., 2006; Papazafiropoulou et al. 2009). The differences could be due to genetic, environmental or other confounders. Also this study reveals that smokers had higher chances of developing T2DM than non smokers. Cigarette smoking is an independent risk factor for type 2 diabetes and it has been found that current smokers have an increased risk of developing diabetes compared with non-smokers (Bodemann et al., 2007; Ekpenyong et al., 2012). However, in a study in Nigeria smoking status was found to be a significant factor in males only (Ekpenyong et al., 2012).

A significant number of the respondents had little or no knowledge of T2DM. Majority of the subjects did not know the risk factors as well as symptoms for developing T2DM. Lack of exposure to diabetic patients and lack of interest in issues unrelated to them may be the possible explanation for the low scores. For those who were aware knew the disease only by the Kiswahili name "Kisukari", and failed to understand the word diabetes mellitus. The study revealed that, awareness 
about the disease was more related to the affected family member rather than the national education system. Most respondents had no knowledge about the pathophysiology of the disease, preventive measures, and the possible outcomes of the disease. The respondent's poor knowledge of the pathophysiology of diabetes showed up again in the other questions. Only few knew the complications of T2DM. This poor knowledge may render the general public to be less prudent in taking measures to prevent diabetes. There is a need to highlight the social and economic impact of diabetes in future educational programmes so that the general public would have a better understanding of the severity of the disease. Findings of this study were similar to those by Saleem et al. (2009) who reported that knowledge of diabetes mellitus is confined to those with T2DM disease and their relatives.

In conclusion, findings of this study showed very high prevalence of T2DM in Mwanza city as affecting mostly individuals 40-60 years old. Significant independent associations were found for age, sex, first relative with T2DM, and smoking with T2DM. The findings also indicate that knowledge and awareness about T2DM is minimal among Mwanza City residents. It is therefore recommended that awareness about T2DM should be raised starting from young age. Routine checks of blood glucose levels should be done frequently for all adults above 35 years. Health education on causes, risk factors and management of T2DM should be promoted and people should be encouraged to report to health facilities whenever they observe symptoms of T2DM. This would help to control the disease before secondary stage complications develop.

\section{References}

Aspray, T., Mugusi, F.S., Whiting, D., Edwards J., Albert, K.G. \& Unwin, N. C. (2000) Rural and urban differences in diabetes prevalence in Tanzania: The role of obesity, physical inactivity and urban living. Transactions of the Royal Society of Tropical Medicine and Hygiene 94, 637-644.

Bodenmann, W.C.P., Ghali, W.A., Faris, P.D. \& Cornuz, J. (2007) Active smoking and the risk of type 2 diabetes: a systematic review and meta-analysis. Journal of American Medical Association. 298, 2654-2664.

Chamnan, P., Simmons, R.K., Forouhi, N.G., Luben R. Khaw, K.Y., Wareham, N.J. \& Griffin SJ (2011) Incidence of type 2 diabetes using proposed HbA1C diagnostic criteria in the EPIC-Norflok cohort: Implication for preventive strategies. Diabetes Care 34, 950-956.

Cowie, C.C., Rust, K.F., Byrd-Holt, D.D., Eberhardt, Flegal, K.M., Engelgau, M.M., Saydah, S.S., Williams, D.E., Geiss, L.S. \& Gregg, E.W. (2006) Prevalence of Diabetes and Impaired Fasting Glucose in Adults in the U.S. Population: National Health and Nutrition Examination Survey 1999-2002. Diabetes Care 29, 1263-1268.

Cullen, K.W. \& Buzek, B.B. (2009) Knowledge About Type 2 Diabetes Risk and Prevention of AfricanAmerican and Hispanic Adults and Adolescents With Family History of Type 2 Diabetes. The Diabetes Educator 35, 836-842.

Daniel, W.W. (1999) Biostatistics: A Foundation for Analysis in the Health Sciences. $7^{\text {th }}$ Edition . John Wiley \&Sons, New York.

Dart, A., Martons, P.J., Rigatto, C., Brownell, M.D., Dean, J.H. \& Sillers, A.E. (2013) Earlier onset in youth with type 2 diabetes. Diabetes Care 37, 436-443.

Egede, E.L. \& Elis, C. (2010) Diabetes and depression: global perspectives. Diabetes Research and Clinical Practice 87, 302-312.

Ekpenyong, C.E., Akpan, U.P., Ibu, J.O. \& Nyebuk, D.E. (2012) Gender and age specific prevalence and associated risk factors of type 2 diabetes mellitus in Uyo Metropolis, South Eastern Nigeria. Diabetologia Croatica 41-1, 17-28. 
Frank, B.H. (2010) The role of diet, lifestyle, and genes: globalization of diabetes. Diabetes Care 34, 1249-1257.

Gillepsie, S. \& Haddad, B. (2003) The double burden of malnutrition in Asia. Causes, Consequences and Solutions. Washington, D.C International Food policy Research Institute. Soge Publications. 263pp.

IDF (2009) The Global ,Burden. International Diabetes Federation http://.idf.org/files].

Kothari, C.R. (2006) Research Methodology. Methods and Techniques. $2^{\text {nd }}$ edition. New Age International Publisher Ltd. New Delhi. 401pp.

Mahrooqui, B.A, Rahma Al-Hadhrami, R., Al-Amri, A., Al-Tamimi, S., Asma Al-Shidhani, A., Al-Lawati H., A-Ismaili, A., Al-Hooti, K. \& Thamra Al-Ghafri, T. (2013) Self-Reported Knowledge of Diabetes among High School Students in Al-Amerat and Quriyat Sultan Qaboos University Medical Journal 13, 392-398.

Nardo, F., Burattini, R., Cogo, C.E., Faelli, E. \& Ruggeri, P. (2009) Age-related analysis of insulin resistance, body weight and arterial pressure in the Zucker fatty rat. Experimental Physiology 94, 162-168.

Nguma, L.K (2010) Health Seeking and Health Related Behaviour for Type 2 Diabetes Mellitus among Adults in an Urban Community in Tanzania. PhD Thesis, University of Otago, Wellington New Zealand.

MoHSW/IHI/NIMR/WHO (2013) Midterm Analytical Review of Performance of the Health Sector Strategic Plan III 2009 -2015. Ministry of Health and Social Welfare, Dar es Salaam, Tanzania.

OECD (2011), "Diabetes prevalence and incidence", in Health at a Glance 2011: OECD Indicators, OECD Publishing. http://dx.doi.org/10.1787/health_glance-2011-13-en

Papazafiropoulou, A., Sotiropoulos, A., Skliros, E., Kardara, M., Kokolaki, A., Apostolou, O. \& Pappas, S. (2009) Familial history of diabetes and clinical characteristics in Greek subjects with type 2 diabetes. Endocrinology Disorder 9:12.

Ramaiya, K.L., Swai, A.B., McLarty, D.G., Bhopal, R.S. \& Alberti, K.G. (1991) Prevalences of diabetes and cardiovascular disease risk factors in Hindu Indian subcommunities in Tanzania. BMJ 303, 271-276.

Saleem, O.U., Yousaf, R., Tanya, C., Muhammad, A., Aman, F., Maryam, K., Afzal, F.M., Sarwar, A., Shahid, T., Shafiq, S., Asfand, Y. \& Alam, A. (2009) Investigating the awareness level about Diabetes Mellitus and associated factors in Tarlai (Rural Islamabad). Journal of Pakistan Medical Association 59, 798.

Shaw, J.E., Sicree, R.A. \& Zimmet, P.Z. (2010) Global estimates of the prevalence of diabetes for 2010 and 2030. Diabetes Research and Clinical Practices 87, 4-14.

Sobngwi E., Mauvais-Jarvis E., Vexiau P., Mbanya J.C. \& Gautier, J.F. (2001) Diabetes in Africans. Epidemiology and Clinical Specificities. Diabetes and Metabolism 27, 628-634.

TDA (2005) Number of Diabetics in Tanzania Underestimated. Tanzania Diabetes Association Report. http://www.redorbit.com/news/health/306827/number_of_diabetics_in_tanzaniaunderes timate_association/index.html.

Travers, M. \& McCarthy, M. (2011) Type 2 diabetes and obesity: genomics and the clinic. Human Genetics 130, 41-58.

URT (2012) Regional profile. Mwanza Region[http://www.amicaal.org/publications/profil e/Mwanza]. Profile

Wada, K., Tama, K.K., Yatsuya, H., Otsuka, R., Murata, C., Zhang, H., Takefuji, S., Matsushita, K., Sugiura, K. \& Toyoshime, H. (2006) Association between parental histories of hypotension, diabetes and dyslipidemia and the clustering of these disorders in off-spring. Preventive Medicine 42, 358-363. 
Wang, Y., Rimm, E.B., Stampfer, M.J., Willett, W.C. \& Hu, F.B. (2005). Comparison of abdominal adiposity and overall obesity in predicting risk of type 2 diabetes among men. America Journal of Clinical Nutrition 18, 555-563.

Wee, H.L. \& Scli, H.K. (2002) Public awareness of diabetes mellitus in Singapore. Singapore Medical Journal 43, 128-134.

Whiting, D.R., Guariguata, L., Weil, C. \& Shaw, J. (2011) IDF Diabetes Atlas: Global estimates of the prevalence of diabetes for 2011 and 2030. Diabetes Research and Clinical Practice 94, 311-321.

WHO (2004) Appropriate body mass index for Asians populations and its implications for policy and interventions strategies. Lancet 157-163.

WHO (2008a) World Health Organization. Epidemiological Fact Sheet on HIV and AIDS: United Republic of Tanzania 2008.

WHO (2008b) Waist Circumference and Waist-Hip Ratio. Report of a WHO Expert Consultation, Geneva, 8-11 December 2008.

WHO (2009) Global health risks: mortality and burden of disease attributable to selected major risks. Geneva.

WHO (2012) Tanzania STEPS survey-2012: Fact Sheet www.who.int/chp/steps/UR-TanzaniaFactsheet_2012.pdf.

Wild, S., Roglic, G., Green, A., Sincree, R. \& King, H. (2004) Global Prevalence of Diabetes. Estimates for the year 2000 and projections for 2030. Diabetes Care 27, 1047-1053.

Yamashita, K., Kondo, T., Osugi, S., Shimokata, K., Maeda, K., Okumura, N., Matsudaira, K.S., Shintani, S., Muramatsu, T., Matsushita, K. \& Murohara, T. (2012) The significance of measuring body fat percentage determined by bioelectrical impedance analysis for detecting subjects with cardiovascular disease risk factors. Circulation Journal 76, 24352442 . 